\title{
Minorias, Política e Violência
}

\author{
Minorities, Politics and Violence
}

\section{RESUMO}

Neste pequeno ensaio traçarei, em linhas gerais, a condição das mulheres no Brasil apontando a correlação entre as tentativas de alteração da subalternidade feminina através do novo Código Civil. Analisarei como, ao mudar a "forma da Lei" resultaram reações danosas para as mulheres como o crescimento da violência e a sua exclusão no campo da representação eleitoral.

Palavras-chave: Gênero. Mulher. Minorias. Código Civil. Representatividade.

\section{ABSTRACT}

In this little essay I have traced, in general lines, the women's condition in Brazil signalling the correlation between the attempts of changing the feminine subalternity through the new Civil Code. I have analysed how, while changing the "Law's form" resulted in harmful reactions to the women as the growth of violence and their exclusion in the electoral representation field.

Keywords: Gender. Woman. Minorities. Civil Code. Representativity.

\section{SÃO AS MULHERES UMA MINORIA?}

A organização deste dossiê sobre minorias incluiu as mulheres. Mas são as mulheres uma minoria? A inclusão me pareceu paradoxal, pois as mulheres, no Brasil, são mais da metade da população (51,4\%). Fui buscar um esclarecimento no Dicionário Aurélio para entender o significado atribuído à palavra - minoria. Li que há dois sentidos: minoria é um substantivo feminino que significa uma "inferioridade numérica"; ou, pode ser "a parte menos numerosa duma corporação deliberativa e que sustenta ideias contrárias às do maior numero". Ora, não somos numericamente inferiores. E também não somos uma parte menor de uma corporação que delibera, ao contrario,

Eva Alterman Blay

Universidade de São Paulo. Faculdade de Filosofia, Letras e Ciências Humanas, São Paulo. Brasil. 
constituímos uma maioria submetida a uma minoria que tem o poder de decisão.

No imaginário brasileiro, as mulheres são tidas como pessoas incapazes de decidir, incompetentes, frágeis, infantis. Resta analisar como e porque a imagem da mulher é desqualificada.

As mulheres constituem uma camada heterogênea, complexa, composta de pessoas de todas as etnias, cores, orientações sexuais, classes sociais, nível educacional, etc. Não há uma mulher, há mulheres $[6 ; 7]$.

Uma rápida observação socio-demografica mostra que no Brasil 1/3 dos lares são chefiados por mulheres sem a participação masculina, são apenas elas e seus filhos. As mulheres, sozinhas, cuidam econômica e socialmente das famílias. A carência masculina nos grupos familiares tão consistente é ocultada através de piadinhas machistas que reduzem, desumanizam as mulheres: estão sozinhas, são mal amadas, são mães solteiras, além de expressões mais vulgares.

Piadas refletem modos de pensar, escancaram ideologias, valores, e no caso, a versão machista da subjetividade, reproduzem falsas verdades. Basta ver as propagandas da cerveja, do Carnaval, para observar que não se vendem bebidas, mas os seios ou partes intimas do corpo de uma mulher. Rindo encobrimos problemas. Deixamos de perguntar, por exemplo, porque há mais mulheres do que homens. Berquó [2]., entre outros, mostrou que na população nascem mais meninos que meninas; contudo estes morrem nos primeiros anos de vida mais do que as meninas levando a um equilíbrio da população infantil do ponto de vista do sexo biológico. A história tem mostrado que quando há guerras, a população se desequilibra, os homens morrem mais nas batalhas. Pode-se argumentar que o Brasil não está em guerra. Há outros tipos de guerra e os dados mostram que a violência urbana, o racismo, os homicídios, sobretudo de homens jovens, negros, provocam enorme redução da população masculina.

\section{CONTRADIÇÕES: PERSISTÊNCIA DE PADRÕES PATRIARCAIS NOS SÉCULOS XX E XXI}

Desde a segunda metade do século XX até a primeira década do XXI houve crescimento e diversificação da força de trabalho feminina. Entraram cerca de 12 milhões de novas trabalhadoras entre 1985 e 1995 elevando a taxa de participação feminina para $53,4 \%$ ou seja, 40,4\% da força de trabalho era de mulheres [5]. Praticamente não há setor em que as mulheres não trabalhem, porém, a inclusão é diferencial tanto na formação educacional quanto no trabalho: entraram na Saúde, nas Engenharias, nas Ciências Exatas, mas formaram nichos femininos nessas profissões. Na Saúde dirigem-se para Enfermagem, para a Pediatria, para Fonoaudiologia, Fisioterapia, etc. Nas Engenharias prevalecem na Química, Engenharia de Alimentos, etc. Predominam nas Ciências Humanas e, mesmo nestas, raramente nas posições mais elevadas e de maior remuneração.

Os movimentos feministas têm se debruçado sobre os fatores que desestimulam as meninas para as carreiras cientificas (as hard Science) e apontam como a socialização as induz à maternidade e a tarefas do cuidado doméstico.

Desde o passado patriarcal gerar filhos era o destino das mulheres. A gestação, o 
parto, a amamentação, era e continuam sendo considerados a "essência do feminino". O que seria essa essência? Desmistificar a visão ideológica dessa essência foi objeto de varias autoras (es) $[1 ; 4]$. Desconstruir o mito da maternidade, desnaturalizar esse conceito é tarefa ainda em construção. Gerar filhos não é condição para todas as mulheres, cuidar é tarefa que as ocupariam nos primeiros meses de vida da criança. Estender a função materna para o resto da vida é uma idealização da maternidade que foi cantada em verso e prosa por alguns homens. Não se discutia, por exemplo, que nas sociedades escravocratas, ou nas burguesas, a alta burguesia, não eram as mães que cuidavam e amamentavam seus filhos.

A maternidade foi argumento usado para excluir as mulheres de várias atividades sociais: no passado se alegava que as mulheres não tinham direito ao voto, pois ficariam impossibilitadas para suas atividades maternas.

Atualmente, século XXI, essa função é romantizada e apregoada pela televisão, revistas e novelas: basta observar a contradição entre o padrão comportamental daquelas que possuem muitos recursos financeiros e o real quotidiano das diferentes classes sociais. Mas, como mostrou Bosi, a fantasia atravessa os sonhos das mulheres da camada trabalhadora [3].

A medicina e certas politicas publicas atribuem a exclusividade de tudo que diz respeito à maternidade à mulher. Observem-se as políticas de incentivo ao aleitamento em que se recomenda em que a criança deve ficar no peito por tempo indefinido! Não discuto os benefícios do aleitamento, mas analisemos que ele não é único nem se justifica manter a criança ao peito por meses, um ano, dois anos... Então seria essa recomendação uma maneira de esconder que a família não possui recursos para comprar outros alimentos? Ou porque o Estado não quer gastar recursos para alimentar a nova geração? É perverso fazer a mulher sentir-se culpada por não poder amamentar a criança, pois trabalha dentro e fora de casa, tem outros filhos, etc.

O marketing da amamentação é cruelmente fortalecido pelo uso de famosas atrizes amamentando nas revistas, na TV. Claro que não se conhece o que há de real por trás da imagem.

O outro lado desse quadro desestabilizador é afastar o pai dos filhos e filhas. A exclusividade dada à mulher do cuidado materno e doméstico ignora uma possível divisão do trabalho físico e afetivo: sobrecarrega a mulher e afasta o homem de acompanhar o desenvolvimento de laços importantes para com a nova geração.

Foram necessárias algumas décadas de debates feministas para repensar essa relação de amor, procriação e cuidado divididos com homens e mulheres. No Brasil estamos mal dando os primeiros passos nesta direção.

O desempenho das atividades domésticas atribuído às mulheres modelou a divisão do trabalho profissional: a professora se torna a tia, a secretaria bilíngue serve café e faz tarefas nada vinculadas a seu cargo; a médica é induzida a buscar trabalho com horários que lhe permitam cuidar da casa, do marido e dos filhos. Entre as consequências dessa desigual divisão de tarefas pode se constatar pelas dificuldades na trajetória profissional das mulheres. A universidade é exemplar quando se analisam as carreiras acadêmicas dos casais onde a dos homens é mais rápida e ascendente, enquanto a das mulheres, suas esposas, é lenta ou estaciona. 
Entramos no século XX com uma legislação em que o Código Civil, aprovado em 1916, regia as relações entre homens e mulheres. Dizia o artigo 2 desse Código': "Todo homem é capaz de direitos e obrigações na ordem civil". Homem não era um termo figurado, referia-se ao individuo do sexo masculino. Em 1916 a mulher, quando solteira, estava subordinada ao pai; casada passava a ser "companheira e colaboradora nos encargos de família, cumprindo-lhe velar pela direção material e moral desta”. Portanto, era companheira, era assessória, não era protagonista. A mulher precisava da autorização do marido para trabalhar, fazer compras mais volumosas mesmo com seu próprio dinheiro. $\mathrm{O}$ homem era o chefe da família. Cabia a ele determinar o lugar de residência da esposa e dos filhos, administrar o patrimônio.

O Código de 1916 perdurou por 50 anos garantindo a relação de poder e subordinação da mulher ao chefe da família. A lei rege o comportamento, garantido pela punição legal. Represente ou não o consenso da época a lei obrigava os indivíduos a se pautarem por ela. O Código Civil foi elaborado traduzindo os valores da época e alimentando, nas décadas seguintes, os mesmos padrões. Isso não significa que fossem perenes, ao contrario as mulheres procuraram se libertar das condições subalternas.

Foram muitos os impasses durante os 50 anos nos quais o país nem sempre viveu democraticamente (1930 a 1945, a ditadura de Getúlio Vargas). Modificar a condição subalterna da mulher casada foi um objetivo que mobilizou várias organizações femininas.

Figura ímpar nesse processo foi Romy Medeiros da Fonseca (1921-2013). Advogada, casada com um advogado, Romy o acompanhou em uma viagem aos Estados Unidos onde ela presenciou a atuação das feministas por novos direitos. Voltando ao Brasil ela se uniu a advogada Orminda Ribeiro Bastos (1899-1971), e ambas elaboraram um texto preliminar da lei para alterar o Código Civil dando à mulher o mesmo status do marido na família. Nesse meio tempo Romy quis apresentar seu projeto numa reunião fora do Brasil. Ironicamente seu marido, jurista, usando de seu poder legal, não lhe permitiu viajar. Diante de sua insistência finalmente concordou desde que ela fosse acompanhada . pelo seu irmão!

Na volta Romy e Orminda elaboraram e encaminharam o projeto ao Senador Mozart Lago. Esse previa que se excluísse a incapacidade jurídica das mulheres casadas. O Projeto ficou no Congresso por 11 anos, desde 1951e sua aprovação se deu em 1962, quando o Presidente João Goulart o assinou em 27 de agosto de 1962. É, o que viria a ser o Estatuto da Mulher Casada.

\section{ENTRE A LEI E A REALIDADE: VIOLÊNCIA E EXCLUSÃO POLÍTICA}

Ao modificar o status da mulher casada operou-se um passo na direção da cidadania das mulheres. Legalmente houve uma ruptura no vínculo legal marido-esposa. Com

$1 \quad$ Lei 3.071 , de $1^{\circ}$ de janeiro de 1916. 
essa pequena libertação, a mulher não mais precisaria pedir autorização ao marido para trabalhar, ganhar seu próprio dinheiro. Ele não poderia mais decidir, sem que ela fosse consultada, sobre o local de residência do casal. A redução formal da autoridade masculina não foi aceita passivamente. As crises entre casais na vida quotidiana revelam que pouco mudou e, ao contrário, reações violentas se tornaram constantes. Contudo, mesmo com o Estatuto da Mulher Casada, permaneceram outros dispositivos legais, que retiravam a autonomia da mulher. Exemplo era o Código de Processo Penal que determinava que a mulher casada não pudesse fazer um boletim de ocorrência policial sem a presença do marido.

Mudou a Lei, mas teriam se alterado os valores e comportamentos de subordinação da mulher como previa o Código Civil de 1916? Se a igualdade é plena, por que ainda hoje os homens não aceitam quando as mulheres querem romper uma relação conjugal? A violência contra a mulher - simplesmente por ela ser mulher - é extremamente elevada. Trata-se de uma violência contra a independência feminina. Frases como "bato porque é minha", "mato porque tenho o direito", "prendo em casa porque posso", indicam que a mentalidade machista de propriedade do corpo feminino prevalece. Essa mulher não é uma cidadã, é mero apêndice da relação definida pelo homem.

Nos últimos 40 anos as mulheres, especialmente os movimentos feministas, lutaram para que o Estado reconhecesse a violência contra a mulher simplesmente por ela ser mulher (o que algumas autoras chamam de violência de gênero).

O caminho foi longo [2] como podemos ver ao longo dos anos. Tomarei apenas alguns momentos cruciais a partir de 1975, o Ano Internacional da Mulher, quando em plena ditadura os movimentos de mulheres puderam, sob a salvaguarda da $\mathrm{OAB}$ e da ONU se reunir e apontar os enormes problemas que vivíamos. Até então vigorava o direito de matar a companheira sob a justificativa de "defesa da honra". $\mathrm{O}$ assassinato de Angela Diniz, em 1976, por seu namorado de alguns meses, Doca Street, provocou uma forte reação das mulheres. Foi o momento de consagração da expressão "quem ama não mata". Essa frase repetida continuamente levou à condenação do assassino praticamente excluindo a justificativa do assassinato das companheiras sob o argumento de "defesa da honra".

A partir de então, em vários estados do Brasil, se viu serem criados centros de atendimento à mulher, como o SOS Mulher (1979-1980).

Com a redemocratização começa uma nova etapa no movimento de mulheres: feministas se articulam com o Estado criando Conselhos da Condição Feminina (1982 - o primeiro foi o de São Paulo). Cresceram as denuncias de violência contra a mulher o que levou a que em 1985 fosse criada $1^{\text {a }}$ Delegacia de Defesa da Mulher no Estado de São Paulo. Desde então foram sendo criados em vários locais delegacias, conselhos, e algumas poucas casas-abrigo, até que em 1988 quando o Estado foi obrigado a coibir a violência no âmbito domestico (art. 226).

A violência praticada contra a mulher era banalizada, reduzida a destemperos familiares. Tanto que a interpretação da lei era feita sob esse pressuposto. Assim, foi comum e corriqueiro o enquadramento equivocado do crime na Lei 9.099, que trata de crimes de menor potencial ofensivo. Por essa lei houve um incentivo à perpetuação da violência cuja penalidade era comprar uma cesta básica para alguma entidade 
filantrópica. O Poder Judiciário, nesse sentido, foi leniente aceitando o cumprimento de penas como cesta básica e até ramos de flores, propostas de iniciativa no Ministério Público, representando a Justiça Pública.

O quadro muda posteriormente quando organizações feministas conseguem que, para não ser condenado pela Comissão Interamericana de Direitos Humanos, o Brasil aprovou a lei 11.340, a Lei Maria da Penha.

Os avanços são muito contraditórios. Os movimentos feministas não param de denunciar a violência e mortes de mulheres por causas perfeitamente evitáveis, como na interrupção da gravidez.

As inovações, referentes aos direitos e garantias individuais, trazidas na Constituição da República vigente, foram incapazes de afastar valores presentes na cultura nacional. Se homens e mulheres são iguais frente aos direitos e deveres que garantem o pleno exercício da cidadania, questões gravíssimas ainda são repelidas, como o direito ao aborto. $\mathrm{O}$ atraso é medido pelo próprio marco constitucional. Somente em 1997 foi revogado o dispositivo que não permitia que a mulher casada fizesse um B.O.

Apesar da aprovação da capacidade jurídica das mulheres (casadas) aprovada em 1962, isso não significou que a mulher tivesse direito sobre seu próprio corpo. A legislação, majoritariamente feita por homens, não se dispõe a discutir um tema que diz respeito ao corpo feminino e, quando o faz, adota uma posição maternalista. Não distinguem o direito da mulher ao seu próprio corpo. O papel de algumas igrejas fortalece essa posição contrária ao direito de interromper a gestação. $\mathrm{O}$ máximo que se consegue é garantir que a interrupção seja feita em casos de estupro ou risco de vida da mulher, e mesmo assim com muitas dificuldades face à rejeição do procedimento alegada por profissionais por razão de consciência.

Discutir a enorme controvérsia sobre o abortamento, procedimento aprovado em praticamente todo o mundo, mereceria um outro artigo. Vale apenas apontar que embora seja proibido no Brasil, as mulheres o fazem, e as pobres se submetem a condições que levam com frequência à morte: é a $4^{\mathrm{a}}$ causa de mortes maternas no Brasil[8].

\section{QUANDO OS HOMENS LEGISLAM}

Considere-se que no Parlamento brasileiro somos 9,9\% (quando, no mundo, somos $22,2 \%$ ), portanto, são os homens (parlamentares mais os homens da igreja) é que impedem o acesso das mulheres à saúde reprodutiva integral.

O panorama traçado revela que a lei mantém a proteção aos homens conservadores que se consideram no direito de vida e morte sobre as mulheres.

Finalmente uma última reflexão sobre o Estado, o parlamento e as condições de gênero. A organização legislativa democrática pós-1988 preservou os valores patriarcais. Ter uma mulher na presidência da república é meramente circunstancial e resultou de forças políticas que preservavam o machismo e a exclusão das mulheres do poder. Não houve alterações que garantissem os direitos das mulheres na estrutura do Estado ou dos partidos políticos. Alterações no campo das leis não se refletiram suficientemente na cultura anti-feminista. Vivemos ainda sob os irrisórios avanços de 1916. 
Assim, vale recolocar a questão que coloquei no inicio desse texto: são as mulheres minoria?

\section{REFERÊNCIAS}

[1] BADINTER, E. Um Amor Conquistado: o Mito do Amor Materno. Rio de Janeiro: Nova Fronteira, 1985.

[2] BERQUÓ, E. S. A importância dos estudos sobre população negra. Jornal da Rede Saúde. , p. 11-16, 2001.

[3] BLAY, Eva Alterman. Assassinato de Mulheres e Direitos Humanos. São Paulo: Editora 34, 2013.

[4] BOSI, Ecléa. Cultura de massa e cultura popular: Leituras operárias. Petrópolis: Vozes, 2000.

[5] COSTA, J. F. Ordem Médica e Norma Familiar. Rio de Janeiro: Graal, 1987.

[6] GUIMARÃES, N. A. Caminhos Cruzados: Estratégias de empresas e trajetórias de trabalhadores. São Paulo: Editora 34, 2004.

[7] PERROT, Michelle. "Práticas da Memória Feminina". Revista Brasileira de História, São Paulo, v.9, n.18, ago-set. 1989, p.13;

[8] Portal Brasil. OMS: Brasil reduz mortalidade materna em 43\% de 1990 a 2013. Saúde das mulheres. Disponível em: <http://www.brasil.gov.br/saude/2014/o5/oms-brasil-reduz-mortalidade-materna-em-43-de-1990-a-2013. Acesso em: 04 abr. 2016>.

[9] SCOT, Joan W. Gender and Politics of History. New York: Columbia University Press, 1999.

[10] FLACSO BRASIL. Mapa da Violência 2015: Homicídio de Mulheres no Brasil. Disponível em: <http://www.mapadaviolencia.org.br/pdf2015/MapaViolencia_2015_mulheres.pdf $>$. Acesso em: 04 abr. 2016.

\section{AGRADECIMENTOS}

Agradeço a Adriana Gragnani a leitura e as sugestões e a leitura atenciosa de Flavia Rios.

eVA A lterman blay é Professora Titular Sênior da Universidade de São Paulo, pós-doutora pela École dês Hautes Études en Sciences Sociales. Criou o primeiro curso de graduação e pós-graduação sobre a mulher na Universidade de São Paulo. Foi fundadora e Presidente do Centro de Estudos Rurais e Urbanos. Fundou o NEMGE, Núcleo de Estudos da Mulher e Relações Sociais de Gênero; foi a primeira Presidenta do Conselho Estadual da Condição Feminina do Estado de Paulo. Senadora da República entre dezembro de 1992 e janeiro de 1995. Coordenadora do Escritório USP MULHER, ligadò̀ ONU-e-mail: eblay@usp.br. 